\title{
Ação formativa para o desenvolvimento de competências no setor de referência
}

\author{
Training action for the development of competences in the reference sector
}

\author{
Maria Giovanna Guedes Farias \\ Doutora em Ciência da Informação pela Universidade Federal da Bahia - UFBA. \\ Professora do Programa de Pós-Graduação em Ciência da Informação e do Departamento de Ciências da \\ Informação da Universidade Federal do Ceará - UFC. \\ E-mail: mgiovannaguedes@ gmail.com
}

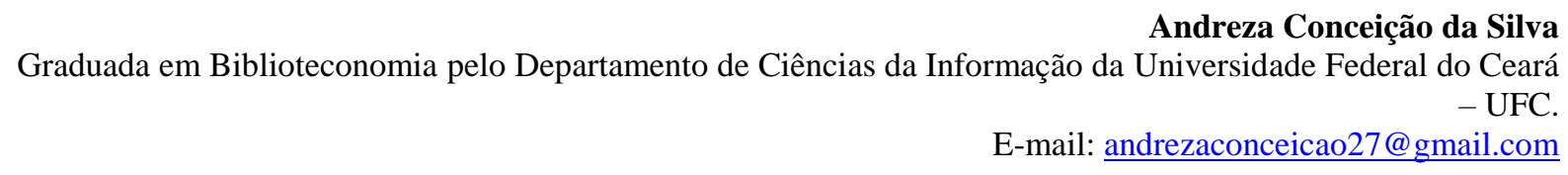

\section{Resumo}

Apresenta resultados de pesquisa em andamento no setor de referência de duas bibliotecas universitárias. A primeira fase desta investigação descobriu quais competências os bibliotecários das bibliotecas pesquisadas possuem, as que precisam ser desenvolvidas e as que precisam ser potencializadas para atuação no setor de referência. Para tanto usou a abordagem qualitativa e os princípios da pesquisa participante. Os dados foram coletados por meio de roteiro de entrevista, formulário de prospecção e diário de campo e foram analisados a partir da técnica de análise do conteúdo. A segunda e atual fase da pesquisa, objetivo deste artigo, enfatiza a preparação de uma ação formativa (capacitação) com a finalidade de impulsionar os sujeitos da pesquisa a refletirem acerca do que vivenciam no dia a dia no ambiente de trabalho, quais as competências que utilizam e quais poderiam ser desenvolvidas para melhor atender ao usuário. $\mathrm{O}$ foco da capacitação se dá às etapas do processo de referência e seus desdobramentos na realidade cotidiana dos bibliotecários. A partir desta ação nas bibliotecas pesquisadas, os bibliotecários devem compreender a importância de atuar como protagonistas do seu ambiente de trabalho, promovendo a autorreflexão sobre suas ações junto aos usuários e também sobre as possibilidades de melhorar o atendimento, pensando nas competências em informação que já detêm e nas que precisam ser desenvolvidas ou aprimoradas, a fim de proporcionar a ampliação de seus repertórios de competências com foco na melhoria dos serviços prestados.

Palavras-Chave: Competências em informação. Setor de referência. Biblioteca universitária. Bibliotecário. Ação formativa.

\begin{abstract}
Presents ongoing research results in the reference sector of two university libraries. The first phase of this research discovered which competencies the librarians of the libraries researched possess, those that need to be developed and those that need to be potentiated to work in the reference sector. For this he used the qualitative approach and the principles of the participant research. Data were collected through interview script, prospecting form and field diary and were analyzed using the content analysis technique. The second and current phase of the research, objective of this article, emphasizes the preparation of a training action with the purpose of impelling the research subjects to reflect on what they experience in the work environment, what skills and which could be developed to better serve the user. The focus of training is on the steps of the reference process and its unfolding in the daily reality of librarians. From this action in the researched libraries, librarians should understand the importance of acting as protagonists of their work environment, promoting self-reflection about their actions with users and also about the possibilities of improving care, thinking about the information skills that already and in those that need to be developed or improved, in order to provide the expansion of their repertoires of competencies focused on improving the services provided.
\end{abstract}

Keywords: Information literacy. Reference sector. University library. Librarian. Training action. 


\section{Introdução}

A formação acadêmica aliada à prática cotidiana reforça a atuação do bibliotecário como mediador do saber, não somente, mas, especificamente, no setor de referência, exigindo deste profissional conhecimentos, habilidades e atitudes que o auxiliem na execução de serviços de forma eficiente. Entretanto, os desafios diários da vida do bibliotecário podem impedi-lo de refletir a respeito de suas práticas laborais, a exemplo de como está conduzindo o atendimento aos usuários. Compreendemos este atendimento como uma ação permeada de responsabilidade social, pois o usuário ao fazer uso efetivo das informações recuperadas pode intervir na sociedade, provocar mudanças e transformações no meio em que vive.

Nesta perspectiva, percebemos a relevância de o bibliotecário ampliar seu repertório de competências em informação (Coinfo), a fim de colocar em prática estratégias que venham despertar nos usuários o desejo e a consciência da relevância da autoaprendizagem, a qual oportuniza o crescimento pessoal dos indivíduos, proporcionando a autonomia nos estudos. Para tal, o bibliotecário de referência é o personagem incumbido da missão de atender as necessidades informacionais dos usuários, para tanto, precisa conhecer seu público, as fontes de informação e os critérios de busca e recuperação no intuito de disponibilizar o que é mais relevante.

Essas reflexões conduzem esta pesquisa que está em andamento no setor de referência de duas bibliotecas universitárias (BU), campo de estudo escolhido por ter como função social o aprimoramento de serviços para a comunidade acadêmica e o auxílio ao desenvolvimento da ciência, educação e cultura. Deste modo, as BU's manifestam-se como um expoente imprescindível na vida acadêmica, favorecendo o crescimento intelectual e trazendo benefícios à sociedade.

Tais entendimentos fortalecem a ideia de que as bibliotecas universitárias, por meio da gestão de seu patrimônio informacional e do exercício de uma função educativa, possuem relevância no contexto de aprendizagem de sua comunidade, indo além da preocupação em oferecer o conhecimento em seus diversos suportes, promovendo ações que buscam potencializar o desenvolvimento acadêmico de seu público, o que significa reinventar-se enquanto unidade de informação.

Para que isso ocorra, os bibliotecários devem atuar como protagonistas do seu ambiente de trabalho, promovendo a autorreflexão sobre suas ações junto aos usuários e também sobre 
as possibilidades de melhorar o atendimento, pensando nas competências em informação que já detêm e as que precisam ser desenvolvidas ou aprimoradas. Foi com esse foco que atuamos dentro do campo de pesquisa, investigando quais as competências que os bibliotecários dessas duas bibliotecas já possuem, quais precisam ser desenvolvidas e quais precisam ser potencializadas para atuação no setor de referência. Os resultados nos conduziram a montar uma ação formativa em formato de capacitação com a finalidade de impulsionar os sujeitos da pesquisa a refletirem acerca do que vivenciam no dia a dia no ambiente de trabalho, e quais as competências que utilizam e quais poderiam ser desenvolvidas para melhor atender ao usuário, e para isso, iremos trabalhar com as etapas do processo de referência e seus desdobramentos na realidade cotidiana dos bibliotecários.

\section{Competência em informação: conceitos e abordagens}

O termo competência em informação (information literacy) sucede às atividades realizadas no contexto das bibliotecas escolares americanas, que no início da década de 50 tinham como foco a instrução dos usuários e objetivavam ensinar os alunos a trabalhar com as fontes de informação que fossem pertinentes ao seu aprendizado. Essa ideia evoluiu e mais tarde, em 1974, foi cunhado o termo competência em informação (CAMPELLO, 2003). Ainda de acordo com Campello (2003, p. 29), ele tem sido usado para:

Designar habilidades ligadas ao uso da informação eletrônica, ele foi assimilado pela
classe bibliotecária e atualmente insere-se de forma vigorosa no discurso dos
bibliotecários americanos, sendo alvo de interesse crescente por parte de
bibliotecários de outros países [...].

Isto demonstra o foco no ambiente digital e a preocupação dos bibliotecários em manterem-se atualizados em relação aos avanços nas formas de comunicação. Perceber e inserir aspectos tecnológicos nas práticas bibliotecárias é estar atento aos usuários e nas transformações em que este está envolto. Na literatura encontramos o conceito formulado por Bruce, que traz uma concepção mais abrangente, enunciando que:

A competência em informação é geralmente descrita como a capacidade de localizar,
gerenciar e utilizar informações de forma eficaz para uma variedade de propósitos.
Como tal, é uma importante "habilidade genérica" que permite que as pessoas se
envolvam no processo de tomada de decisão eficaz, resolução de problemas numa
pesquisa. Ela também lhes permite assumir a responsabilidade pela sua própria
aprendizagem continuada nas áreas de interesse pessoal ou profissional. (BRUCE,
2003 , p. 289, tradução nossa).

Dispor de conhecimento para localizar, gerenciar e utilizar a informação em diferentes 
contextos permite ao sujeito fazer uso efetivo da informação, resolver problemas e tomar decisões, por exemplo. Tais capacidades são ampliadas por meio da aprendizagem continuada, funcionando como peças-chave para viver na sociedade da informação. No entendimento de Wallis (2005) information literacy pode ser compreendido como o termo que designa um conjunto de habilidades necessárias para utilizar as tecnologias da informação e comunicação (TIC) de forma efetiva, na busca pela interação no ambiente eletrônico.

Os elementos mais relevantes na Coinfo, sob a percepção de Bundy (2004, p. 4, tradução nossa), são o discernimento crítico frente à informação e uso do raciocínio, ao invés de somente fluência tecnológica, pois "a competência em informação inicia, sustenta e estende-se ao longo da vida de aprendizagem através de habilidades que podem usar tecnologias, mas que são em última instância independente delas", sinalizando que tais habilidades são aprendidas e aprimoradas ao longo do tempo.

A Coinfo traz na essência dos seus conceitos, a preocupação em como um usuário entende as diferentes formas de busca nas fontes e se ele conhece estratégias para filtrar a soma considerável de informações presentes em seu cotidiano, agregado ao fato de compreender como aquela informação será assimilada pelo mesmo e se ela virá a ser aplicada em suas atividades, o que reflete na utilização proveitosa da informação.

$\mathrm{Na}$ literatura o termo competência em informação aparece ligado à ideia de aprendizagem ao longo da vida, o que consiste em avançar na capacidade de criar habilidades para lidar com a informação através de novas experiências e perspectivas, ser autônomo na obtenção das informações e pensar criticamente sobre elas. Nesta perspectiva, Bruce (2003) aponta sete faces referentes à Coinfo, quais sejam:

a) Experiência com a TI - o acesso à informação perpassa pelo uso das tecnologias de informação;

b) Experiência com fontes de informação - relacionada à capacidade do usuário de encontrar as informações de forma independente ou mediada utilizando diferentes fontes disponíveis;

c) Experiência da informação como processo - tem como cerne os processos de informação, a forma como esta será usada para resolver situações novas que requerem o uso do conhecimento;

d) Experiência no controle de informações - requer o controle da informação pelo usuário, consiste em reconhecer informações relevantes que possam vir a ter futuros 
usos;

e) Experiência da construção do conhecimento - refere-se à utilização da informação criticamente, objetivando a construção de uma base de conhecimento pessoal;

f) Experiência da extensão do conhecimento - trabalha com o conhecimento e com as perspectivas pessoais, possibilitando o uso criativo da informação e a construção de novas ideias, por meio de novos pontos de vista;

g) Experiência do conhecimento - relaciona-se à utilização consciente da informação para o bem comum.

Neste panorama, um sujeito competente em informação seria aquele que integra as habilidades de uso das TIC ao entendimento de como acessar as fontes de informação e de como aplicar informações em diferentes circunstâncias para construir conhecimento, a exemplo do bibliotecário, o qual procura sanar as necessidades informacionais dos usuários, surgidas conforme Belkin, Oddy e Brooks (1982, p. 62, tradução nossa) a partir de uma “[...] anomalia reconhecida no estado de conhecimento do usuário a respeito de algum tema ou situação. Em geral, o usuário é incapaz de especificar exatamente o que é necessário para resolver essa anomalia". Em síntese, a necessidade de informação consiste num déficit no conhecimento de um indivíduo sobre determinado assunto, onde o mesmo busca reparar essa falta em lugares como unidades e centros de informação. No entanto, um indivíduo que ainda não desenvolveu competências em informação, não sabe indicar com exatidão o que é preciso para preencher essa lacuna.

Nesta perspectiva, observamos a relevante atuação do bibliotecário, entendido como indivíduo multifacetado que sabe lidar com diferentes situações e pessoas, o qual pode proporcionar aos usuários a efetividade na busca pela informação, auxiliando-os a entender suas necessidades informacionais e, sobretudo, preparando-os para o domínio do universo informacional. Esses bibliotecários, especificamente os do setor de referência, trabalham com um público diversificado, exigente e que prezam pela rapidez na obtenção da informação. Destarte, sobretudo, esses profissionais precisam desenvolver competências preenchendo suas lacunas informacionais e também as dos usuários. 


\section{Bibliotecário no setor de referência}

O serviço de referência (SR) é caracterizado como um serviço de informação, com objetivo precípuo de responder as necessidades informacionais do seu público. Notadamente, é nele que se tem um contato direto com os usuários e suas necessidades específicas de informação. Uma das primeiras menções ao auxílio ao leitor deu-se na primeira conferência da American Library Association (ALA) em 1876, quando Samuel Swett Green mencionou a relevância da assistência ao leitor na utilização do acervo e, ademais, destacou o aspecto educativo da biblioteca (FIGUEIREDO, 1986). Traduzido do termo reference work, o serviço de referência começou a se difundir com o surgimento das primeiras universidades e a criação de um setor independente voltado somente para a assistência aos leitores.

O serviço de referência é "[...] uma atividade essencialmente humana, que atende a uma das necessidades mais profundamente arraigadas da espécie, que é o anseio de conhecer e compreender" (GROGAN, 1995, p. 22). Sendo assim, exige comunicação, onde através da interação entre os sujeitos ocorrem trocas de saberes que são motivadas de um lado, pela necessidade de conhecer e de outro, de fazer ser conhecido. Esse conceito evidencia uma mudança de paradigma centrada no acervo visando o acesso. Nesta nova abordagem, o leitor é o cerne da questão, as ações realizadas se orientam para suas necessidades informacionais e não como anteriormente, onde as atividades versadas na biblioteca se concentravam no livro.

No entendimento de Talavera Ibarra (2000), o SR é responsável por conectar o usuário às fontes de informação, permitindo assim que ele encontre a informação demandada. A ação de localizar as respostas às questões levantadas perpassa pelo entendimento da natureza do problema colocado. Na percepção de Bertrand Calenge (1996, p. 185), o serviço de referência pode ser compreendido como "uma função organizada de resposta personalizada a um pedido explícito de informação documental ou de documentação". O bibliotecário, atento à necessidade do usuário identifica as respostas mais apropriadas aos questionamentos levantados na intenção de fazê-lo sanar a lacuna em seu estado de conhecimento, quando o acervo não corresponde às necessidades sentidas, cabe a esse profissional orientar o mesmo a procurar outra instituição.

As conceituações em torno do serviço de referência designam um processo de comunicação, o qual visa atender as necessidades informacionais dos usuários, encontrando no bibliotecário a figura do mediador que facilita o acesso à informação. Conforme Grogan (1995), 
essa ideia estaria relacionada ao sentido restrito do conceito de SR e não ao seu sentido amplo, que representa todos os esforços realizados pela biblioteca em prol de proporcionar o funcionamento desta unidade.

O processo de referência para Grogan (1995) é composto por oito etapas, a saber: a) problema - o usuário apresenta um problema que o motiva a procurar o bibliotecário; b) necessidade de informação - déficit de conhecimento que impossibilita ao usuário a continuidade do estudo; c) questão inicial - relacionada ao primeiro contato com o bibliotecário, onde o usuário formula uma questão a ser resolvida; d) questão negociada - o bibliotecário busca maiores esclarecimentos para obter maior precisão nos resultados; e) estratégias de busca - a priori é analisado o tema no intuito de identificar conceitos que poderão gerar enunciados apropriados à linguagem do acervo, e a posteriori verifica-se quais seções correspondem à informação desejada e a ordem em que será feita a consulta; f) processo de busca - garantir a flexibilidade para permitir mudanças na forma de busca; g) resposta - momento em que são apresentados os resultados da busca; e h) solução - quando as respostas apresentadas respondem todos os questionamentos do usuário.

Percebemos que o serviço de referência funciona como norteador em meio aos entraves sentidos pelo usuário ao deparar-se com questões que demandam informações específicas. Outrora a finalidade principal do serviço de referência estava concentrada apenas em oferecer respostas às necessidades informacionais apresentadas, atualmente existe a preocupação em educar os usuários para que eles possam ter autonomia na realização de suas pesquisas quanto ao uso dos recursos oferecidos. Cordón Garcia (1996, p. 265, tradução nossa) visualiza a noção educativa no serviço de referência ao afirmar que "Trata-se, em suma, de possibilitar não somente a difusão da informação, mas também a aprendizagem relativa aos modos operativos mais eficazes de captação da mesma por parte dos membros da comunidade". Mais que auxiliar o usuário a encontrar a informação, o bibliotecário tem exercido uma função educativa ao orientar quanto às fontes mais seguras e de maior credibilidade e as melhores estratégias de encontrar o que se deseja nestas fontes.

Com as mudanças que as TIC proporcionam no ambiente informacional, o serviço de referência tem sido impactado positivamente, pois impulsionou e evidenciou a necessidade de evolução deste e do profissional bibliotecário. Muitos autores, a exemplo de Márdero Arellano (2001), Accart (2012) Nakano e Jorente (2014) buscaram discutir em seus trabalhos essa perspectiva do serviço de referência que trata da modalidade virtual/online. Em outros países 
há centenas de serviços em rede que recebem inúmeras questões por dia como o "ask a librarian”, segundo Márdero Arellano (2001), que permite aos usuários remotos consultar o bibliotecário, estendendo assim os recursos da biblioteca para além de suas paredes físicas.

Seja presencial ou virtual, o objetivo é promover o acesso à informação. Grogan (1995, p. 8) acredita que “[...] os usuários das bibliotecas, auxiliados pelos bibliotecários de referência, têm melhores condições de aproveitarem o acervo de uma biblioteca do que fariam sem esta assistência”. Desta maneira, a intervenção realizada pelo bibliotecário procura maximizar os serviços oferecidos pela biblioteca.

As funções inerentes ao serviço de referência na visão de Mangas (2007) são acolher, informar, formar e orientar. É na ocasião da acolhida que ficam as primeiras impressões de um serviço ou de uma instituição, por isto que o acolhimento deve ser feito com simpatia e profissionalismo. No processo de informar são resolvidas as perguntas feitas pelos usuários. $\mathrm{Na}$ formação há o viés educativo da biblioteca, onde se ensina a fazer uso dos recursos e serviços. E, por último, a função orientar está relacionada ao auxílio na localização de um documento no acervo e na orientação bibliográfica, aconselhando na seleção de uma obra ou fonte.

Durante o atendimento o bibliotecário pode provocar o desenvolvimento do pensamento crítico no usuário, a fim de fazê-lo ser capaz de localizar a informação, ler e incorporar o que foi lido as suas pesquisas. Dasgupta (2013) em seu artigo intitulado More than just a "Reference Librarian" apresenta uma técnica de ensino utilizada por ele com alunos de graduação na mesa de referência, que os estimulam a pensar criticamente através da formulação de perguntas, levando-os a repensar e reavaliar o tópico que eles formulam para a pesquisa. Busca com isso incentivar e colaborar para o desenvolvimento da competência em informação em seus usuários.

O trabalho do bibliotecário de referência se faz importante no momento em que ele passa a intervir na forma de busca do usuário, e a direcionar para o bom aproveitamento daquele conteúdo encontrado nas fontes, ou seja, não é interessante somente promover o acesso à informação, para, além disto, está o uso eficiente da mesma, a capacidade de localizar, acessar, avaliar e criar seu conhecimento com base nas informações recolhidas e processadas. Desta forma, os bibliotecários estão envolvidos no processo de ensino-aprendizagem de seus usuários, desempenhando papel preponderante na sociedade contemporânea.

O bibliotecário de referência além de ter domínio das fontes de informação, precisa 
conhecer bem o perfil do público ao qual sua unidade atende para que a comunicação entre ambos flua. No balcão de referência o bibliotecário exerce a função de mediador, intervindo na necessidade informacional, possibilitando o acesso ao conteúdo desejado. Deste modo, deverá possuir competências de caráter técnico próprios da área e:

[...] possuir todas aquelas qualidades necessárias para o contato e o diálogo permanentes com o público, entre as quais [...] a apresentação cuidada, a cortesia, a amabilidade, a capacidade de ouvir, o dinamismo, o bom senso, a paciência, a curiosidade intelectual, o gosto pelo trabalho de pesquisa e investigação e a capacidade de ensinar. (MANGAS, 2007, p. 9)

As competências técnicas requeridas aos bibliotecários são condição sine qua non para a realização de seu labor, contudo as qualidades supracitadas se enquadram no que chamamos de competências comportamentais, as quais são cada vez mais fundamentais para o sucesso de uma organização, principalmente para aqueles profissionais que lidam diretamente com os usuários. As competências comportamentais ou humanas, ao contrário das técnicas - que são desenvolvidas/adquiridas por meio de cursos, treinamentos, palestras, leituras, etc. - são conquistadas por uma constante autorreflexão, autoconhecimento, e fazem parte das habilidades e potencialidades de um indivíduo, isto é, da sua personalidade. Na visão de Leme (2008, p. 15) as competências comportamentais são um "diferencial competitivo e tem impacto em seus resultados, por exemplo, criatividade, flexibilidade, foco em resultados e no cliente, organização, planejamento, liderança, entre outros”.

Neste contexto, visualizamos o bibliotecário como um profissional versátil, que está incumbido, entre outras funções, de responder as questões dos seus usuários, orientando-os na obtenção de informações relevantes e confiáveis, minimizando o tempo gasto com a busca, incentivando-os a participarem de treinamentos, a exemplo das capacitações de normalização, uso das bases de dados e etc. Para tanto, este profissional precisa recorrer ao seu repertório de competências técnicas e comportamentais, acionando esquemas mentais construídos com base em experiências/vivências adquiridas no trato diário com os usuários em diversos setores, principalmente no de referência. 


\section{Trajetória da pesquisa}

Esta pesquisa encontra-se em sua segunda fase. Na primeira objetivamos identificar as competências em informação de sete bibliotecários que atuam no setor de referência de duas bibliotecas universitárias (uma de grande porte e outra de pequeno porte), investigando se as competências empregadas em suas atividades laborais necessitavam ser ampliadas, com vistas a planejar e implantar ações para subsidiar o desenvolvimento de Coinfo.

Os dados coletados foram analisados a partir do estabelecimento das seguintes categorias de análise: necessidades informacionais do usuário; atitude em relação às demandas informacionais específicas; recursos informacionais e critérios utilizados durante a pesquisa; pesquisa bibliográfica para seleção de informações; e utilização de múltiplos saberes em contextos diversos, e também dos seis parâmetros de Le Boterf (2003): saber agir com pertinência; saber mobilizar saberes e conhecimentos em um contexto profissional; saber integrar ou combinar saberes múltiplos e heterogêneos; saber transpor; saber aprender e aprender a aprender; e saber envolver-se.

Esses parâmetros foram previamente adaptados à realidade do setor de referência e serviram de base para a segunda e atual fase da pesquisa, na qual foram analisadas as lacunas de competência em informação dos sujeitos da pesquisa, visando produzir e aplicar uma ação formativa em formato de capacitação, que motive os bibliotecários a compreender a necessidade de desenvolver as Coinfo que faltam em seus repertórios. Essa capacitação objetiva proporcionar a ampliação, por meio de diversas estratégias didáticas, do repertório de competências dos profissionais, tendo por base as respostas dos bibliotecários que ficaram no patamar de "nunca, raramente e às vezes", em relação às categorias de análise acima descritas.

Observamos nos sujeitos da pesquisa a necessidade de ampliar as seguintes competências de acordo com as categorias de análise: selecionar e explorar diversas fontes de informação em suporte impresso e digital; identificar termos que possam descrever a informação necessitada; localizar fontes solicitadas e outras que contemplem a informação desejada; analisar a questão de pesquisa inicial do grupo, a fim de verificar a possibilidade de inserção de dados à pergunta; descartar informações consideradas irrelevantes; procurar sugerir informações adicionais resultantes de pesquisas; recursos informacionais e critérios utilizados durante a pesquisa (categoria); revisar as perguntas da pesquisa original para determinar se são necessárias informações adicionais ou reformulações; analisar os resultados iniciais da 
pesquisa; procurar compreender todas as informações levantadas; utilização de múltiplos saberes em contextos diversos (categoria). Para chegar a essas competências, foram analisados os questionamentos referentes às categorias de análise da primeira fase da pesquisa.

Ao iniciar a montagem da capacitação promovemos um brainstorming, onde esboçamos o que poderia ser feito, os conteúdos que poderíamos abordar, os materiais possíveis de serem utilizados, formas criativas de apresentar uma temática, etc., isso dentro do contexto a que se propõe essa formação. Ao idealizarmos a capacitação denominada "Coinfo no setor de referência de Bibliotecas Universitárias", tivemos a pretensão de trabalhar as etapas do processo de referência e seus desdobramentos na realidade cotidiana dos bibliotecários, a fim de discutir fatores inerentes ao seu labor tais como questões relacionadas a um atendimento cortês, a importância de um bom diálogo na entrevista de referência, etc. Com isso, buscamos relacionar diretamente as competências elencadas, ou seja, as que carecem ser ampliadas ou mesmo desenvolvidas pelos sujeitos da pesquisa, com os oito passos do processo de referência proposto por Grogan (1995). No quadro 1 podemos visualizar esse cotejamento.

Quadro 1 - Etapas do processo de referência segundo Grogan (1995) e competências em informação dos bibliotecários pesquisados a serem ampliadas

\begin{tabular}{|l|l|l|}
\hline $\begin{array}{c}\text { Etapas do serviço } \\
\text { de referência }\end{array}$ & \multicolumn{1}{|c|}{ Características das etapas } & \multicolumn{1}{c|}{$\begin{array}{c}\text { Competências a serem } \\
\text { ampliadas pelos sujeitos da } \\
\text { pesquisa }\end{array}$} \\
\hline Problema & $\begin{array}{l}\text { Questão que atrai a atenção do usuário e que } \\
\text { o leva a procurar a biblioteca. }\end{array}$ & $\begin{array}{l}\text { Intrínseco ao usuário, não há } \\
\text { ainda o contato com o } \\
\text { bibliotecário. }\end{array}$ \\
\hline $\begin{array}{l}\text { Necessidade de } \\
\text { informação }\end{array}$ & $\begin{array}{l}\text { Lacuna de conhecimento que impede o o } \\
\text { usuário de prosseguir sem essa informação. }\end{array}$ & $\begin{array}{l}\text { Intrínseco ao usuário, não há } \\
\text { ainda o contato com o o } \\
\text { bibliotecário. Esse contato } \\
\text { ocorrerá a partir da próxima } \\
\text { etapa. }\end{array}$ \\
\hline Questão inicial & $\begin{array}{l}\text { Primeiro contato do usuário com o o } \\
\text { bibliotecário; o usuário formula a questão a } \\
\text { ser resolvida, delimitando sua necessidade; o } \\
\text { bibliotecário deve demonstrar acessibilidade } \\
\text { e assumir a questão como sendo sua; as } \\
\text { questões, às vezes, são mal elaboradas; o } \\
\text { bibliotecário precisa extrair do usuário o } \\
\text { maior número possível de dados sobre a } \\
\text { necessidade de informação; o bibliotecário } \\
\text { deve apresentar um vocabulário adequado à } \\
\text { busca. }\end{array}$ & $\begin{array}{l}\text { Identificar termos que possam } \\
\text { descrever a informação } \\
\text { necessitada. }\end{array}$ \\
$\begin{array}{l}\text { Analisar a questão inicial do } \\
\text { grupo, com o objetivo de } \\
\text { verificar a possibilidade de } \\
\text { inserção de dados à pergunta. }\end{array}$ \\
\hline
\end{tabular}




\begin{tabular}{|c|c|c|}
\hline Questão negociada & $\begin{array}{l}\text { O bibliotecário busca esclarecimentos sobre a } \\
\text { questão, a qual é comparada com a forma que } \\
\text { as informações são organizadas na biblioteca. } \\
\text { A comunicação é um fator relevante, bem } \\
\text { como a atualização constante do } \\
\text { bibliotecário. }\end{array}$ & $\begin{array}{l}\text { Descartar informações que } \\
\text { considerar irrelevantes. } \\
\text { (O não descarte de informações } \\
\text { irrelevantes pode gerar um } \\
\text { ruído no atendimento das } \\
\text { necessidades de informação } \\
\text { dos usuários, pois ocasiona } \\
\text { uma perda na qualidade da } \\
\text { pesquisa). }\end{array}$ \\
\hline Estratégias de busca & $\begin{array}{l}\text { O tema é analisado com objetivo de } \\
\text { identificar conceitos que estejam em sintonia } \\
\text { com a linguagem do acervo; definem-se } \\
\text { possíveis caminhos para a pesquisa; o êxito } \\
\text { da busca dependerá do conhecimento íntimo } \\
\text { das várias fontes de informação disponíveis, } \\
\text { experiência em sua utilização e intuição do } \\
\text { profissional; identificam-se as fontes de } \\
\text { informação mais pertinentes; é requerida a } \\
\text { atualização do bibliotecário quanto às fontes } \\
\text { de informação. }\end{array}$ & $\begin{array}{l}\text { Selecionar os recursos } \\
\text { informacionais e critérios } \\
\text { utilizados durante a pesquisa. }\end{array}$ \\
\hline Processo de busca & $\begin{array}{l}\text { Flexibilidade na busca para permitir } \\
\text { mudanças na forma de pesquisa; estratégias } \\
\text { alternativas de busca. }\end{array}$ & $\begin{array}{l}\text { Revisar as perguntas da } \\
\text { pesquisa original para } \\
\text { determinar se são necessárias } \\
\text { informações adicionais ou } \\
\text { reformulações. }\end{array}$ \\
\hline Resposta & $\begin{array}{l}\text { Apresentação dos resultados da busca; o } \\
\text { bibliotecário deve agir de forma democrática, } \\
\text { fornecendo mais de uma opção/resposta } \\
\text { possível para a questão; possibilitar o acesso } \\
\text { a várias fontes; deixar que o usuário decida } \\
\text { sem impor seu modo de pensar; ao usuário } \\
\text { cabe a tomada de decisão sobre qual material } \\
\text { utilizar (TIMBÓ, 2002). }\end{array}$ & $\begin{array}{l}\text { Selecionar e explorar diversas } \\
\text { fontes de informação em } \\
\text { suporte impresso e digital. } \\
\text { Localizar fontes solicitadas } \\
\text { pelos usuários e outras que } \\
\text { contemplem a informação } \\
\text { desejada. } \\
\text { Sugerir informações adicionais } \\
\text { resultantes de pesquisas. } \\
\text { Utilização de múltiplos saberes } \\
\text { em contexto diverso. }\end{array}$ \\
\hline Solução & $\begin{array}{l}\text { As respostas satisfazem a todos os } \\
\text { questionamentos do usuário; o bibliotecário e } \\
\text { o usuário pode avaliar juntos o produto da } \\
\text { pesquisa, a fim de que ambos aprovem a } \\
\text { conclusão do processo. }\end{array}$ & $\begin{array}{l}\text { Analisar os resultados iniciais } \\
\text { da pesquisa. } \\
\text { Procurar compreender todas as } \\
\text { informações levantadas. }\end{array}$ \\
\hline
\end{tabular}

Fonte: Elaborado a partir de Grogan (1995) e dos dados da pesquisa (2017).

Tendo por base esse quadro e a justificativa que sustenta a capacitação, iniciamos a elaboração de um plano de curso. Os objetivos estabelecidos para tal estão apoiados em nosso referencial teórico: apresentar/discutir conceitos de competência em informação; ampliar o conhecimento dos bibliotecários acerca das etapas do processo de referência; e buscar promover por meio do conteúdo programático o desenvolvimento de competências em informação 
requeridas no setor de referência.

Destarte, todo o aporte teórico-conceitual gira em torno da Coinfo, assim também como da análise das etapas do processo de referência, onde buscaremos observar todas as suas nuances, relacionando-as diretamente à competência em informação com o propósito de provocar reflexões sobre a prática cotidiana dos bibliotecários neste setor e as etapas propostas por Grogan (1995).

Para a exposição e discussão destes pontos, a maneira mais apropriada que encontramos foi a utilização do método expositivo dialógico. Pois essa "Estratégia caracteriza-se pela exposição de conteúdos com a participação ativa dos estudantes, considerando o conhecimento prévio dos mesmos, sendo o professor o mediador para que os alunos questionem, interpretem e discutam o objeto de estudo" (NUNES, 2012, p. web). Tal estratégia, centrada no diálogo, possibilita a construção de ideias, não apresenta o mediador como o único detentor de conhecimento. É levado em consideração as experiências e o modo de ver de cada participante. Desta maneira, durante a capacitação objetivamos que ocorra interação entre os participantes, e para isso iremos sugerir atividades que os instiguem a partilhar suas experiências diárias no setor de referência.

Utilizaremos como recursos didáticos textos previamente selecionados, vídeos que trazem experiências vivenciadas pelo bibliotecário no setor de referência, bem como imagens que possam ser problematizadas e discutidas. $\mathrm{O}$ apego a materiais visuais se dá pelo fato de que eles facilitam a associação de ideias e por se tornarem mais fixáveis em nossa memória. Por fim, para avaliarmos se os objetivos da capacitação foram alcançados utilizaremos um questionário, além de grupo focal. No quadro 2 apresentamos o plano de curso com todos esses tópicos especificados: 
Quadro 2 - Plano de curso da Capacitação Coinfo no setor de referência de Bibliotecas Universitárias

\begin{tabular}{|c|c|}
\hline Público-alvo & Bibliotecários do setor de referência de bibliotecas universitárias \\
\hline Justificativa & $\begin{array}{l}\text { A formação acadêmica aliada à prática cotidiana reforça a atuação do } \\
\text { bibliotecário como mediador do saber, não somente, mas, em específico, no } \\
\text { setor de referência exigindo deste profissional habilidades que o auxiliem na } \\
\text { execução de forma eficiente do que lhe é proposto. } \\
\text { Compreende-se que os desafios diários da vida deste profissional podem } \\
\text { impedi-lo de pensar a respeito de suas práticas laborais e da forma como está } \\
\text { conduzindo o atendimento aos usuários e a todas as questões que envolvem a } \\
\text { vivência no setor de referência. } \\
\text { Destarte, essa proposta de capacitação foi criada no intuito de possibilitar e } \\
\text { impulsionar os bibliotecários, sujeitos da pesquisa, a refletirem acerca do que } \\
\text { vivenciam no dia a dia no ambiente de trabalho, e quais as competências que } \\
\text { utilizam e as poderiam ser desenvolvidas para melhor atender ao usuário. } \\
\text { Propõe-se desta maneira, trabalhar as etapas do processo de referência e seus } \\
\text { desdobramentos na realidade cotidiana dos bibliotecários. }\end{array}$ \\
\hline Ementa & $\begin{array}{l}\text { Aporte teórico-conceitual em torno da competência em informação. Análise } \\
\text { das etapas do processo de referência, relacionando-as diretamente à Coinfo. } \\
\text { Reflexão sobre a prática cotidiana dos bibliotecários do setor de referência e as } \\
\text { etapas propostas por Grogan (1995). }\end{array}$ \\
\hline Objetivos & $\begin{array}{l}\text { Apresentar/Discutir o conceito de competência em informação; ampliar o } \\
\text { conhecimento dos bibliotecários acerca das etapas do processo de referência; } \\
\text { buscar promover por meio do conteúdo programático o desenvolvimento de } \\
\text { competências requeridas no setor de referência. }\end{array}$ \\
\hline Competências & $\begin{array}{l}\text { Selecionar e explorar diversas fontes de informação em suporte impresso e } \\
\text { digital; identificar termos que possam descrever a informação necessitada; } \\
\text { localizar fontes solicitadas e outras que contemplem a informação desejada; } \\
\text { analisar a questão de pesquisa inicial do grupo, a fim de verificar a } \\
\text { possibilidade de inserção de dados à pergunta; descartar informações que } \\
\text { considerar irrelevantes; procurar sugerir informações adicionais resultantes de } \\
\text { pesquisa; revisar as perguntas da pesquisa original para determinar se são } \\
\text { necessárias informações adicionais ou reformulações; analisar os resultados } \\
\text { iniciais da pesquisa; procurar compreender todas as informações levantadas; } \\
\text { utilização de múltiplos saberes em contextos diversos. }\end{array}$ \\
\hline $\begin{array}{l}\text { Metodologia de } \\
\text { ensino }\end{array}$ & $\begin{array}{l}\text { A capacitação será ministrada com a utilização de método expositivo dialogado } \\
\text { propiciando a interação entre os participantes por meio de } \\
\text { intervenções/atividades que os instiguem a partilhar experiência/envolver-se } \\
\text { com a capacitação. Além disso, ao final será realizada uma avaliação. Para isso, } \\
\text { seguiremos a seguinte estrutura: apresentação do conteúdo programático e } \\
\text { objetivos; exposição dialógica do conteúdo; síntese do conteúdo abordado; } \\
\text { avaliação. }\end{array}$ \\
\hline Avaliação & $\begin{array}{l}\text { Aplicação de questionário a fim de verificar o alcance dos objetivos, além da } \\
\text { aplicação da técnica de grupo focal. }\end{array}$ \\
\hline
\end{tabular}

Fonte: Elaboração das autoras, 2017. 
Em face do exposto, e com a consciência de que o usuário é o principal expoente de todos os serviços que a biblioteca oferece, pretendemos com essa capacitação aflorar nos sujeitos da pesquisa reflexões que possam ocasionar o desenvolvimento de competências em informação, promovendo assim, um possível aperfeiçoamento no serviço prestado no setor de referência.

\section{Considerações finais}

Compreendemos que o labor do bibliotecário está permeado de responsabilidade social, tendo em vista o objeto com que o mesmo trabalha. O conceito e a empregabilidade do termo informação carrega consigo o poder transformador da realidade social pois, por meio dela passamos a conhecer algo que antes nos era desconhecido, ter consciência de nossos direitos e deveres e ainda o entendimento de nosso papel enquanto sujeitos protagonistas de nossas próprias histórias, o que implica no exercício da cidadania.

Assim, neste entremeio informação e usuário de informação, o bibliotecário busca facilitar o acesso a fontes de informação pertinentes que possam vir a sanar as necessidades do usuário. Para isso, o bibliotecário precisa desenvolver um conjunto de competências que venham auxiliar o usuário em suas atividades de pesquisa de modo efetivo, pensando na possível apropriação da informação feita por este e na consequente aplicação, direta ou indireta, na vida em sociedade.

Destarte, podemos compreender a relevância da competência em informação no desempenho dos bibliotecários, principalmente aqueles do setor de referência. Com base nos achados do estudo da primeira fase, conseguimos identificar as carências dos profissionais no que diz respeito às competências necessárias para atuar no setor de referência, e por meio destas planejar uma ação formativa que viesse ao encontro de tais lacunas.

Essa pesquisa foi delineada visando provocar melhorias nas práticas cotidianas do serviço de referência, e por isso, refletimos sobre a necessidade de atuarmos construindo e aplicando uma ação formativa para impulsionar a ampliação e até mesmo o desenvolvimento da Coinfo nos pesquisados.

Diante disso, os delineamentos futuros para este estudo se concentram na aplicação desta capacitação e no processamento dos resultados, que poderão trazer para os bibliotecários 
de referência, e, consequentemente, para os serviços prestados no setor aos usuários, possíveis aprimoramentos nos processos que envolvem acesso e uso da informação. Esperamos que ao final da pesquisa, os profissionais participantes compreendam a importância de atuarem como protagonistas no trabalho e procurem autonomamente analisar com frequências suas ações, refletindo sobre as competências que detêm e as que precisam ser desenvolvidas.

\section{Referências}

ACCART, J. P. Serviço de referência: do presencial ao virtual. Brasília: Brinquet de Lemos, 2012.

BELKIN, N. J.; ODDY, R. N.; BROOKS, H. M. Ask for information retrieval: part 1. background and theory. Journal of documentation, [s.l.], v. 38, n. 2, 1982. Disponível em: <http://www.emeraldinsight.com/doi/pdfplus/10.1108/eb026722>. Acesso em: 23 ago. 2016.

BRUCE, C. S. Las siete caras de la alfabetización en información en la enseñanza superior. Anales de documentación, Espinardo, n. 6, p. 289-294, 2003. Disponível em: <http://revistas.um.es/analesdoc/article/view/3761/3661 >. Acesso em: 03 out. 2016.

BUNDY, A. Australian and New Zealand information literacy framework: principles, standards and practice. 2. ed. Adelaide: Australian and New Zealand Institute for Information Literacy, 2004. Disponível em: <http://www.caul.edu.au/content/upload/files/infoliteracy/InfoLiteracyFramework.pdf $>$. Acesso em: 04 out. 2016.

CALENGE, B. Accueillir, orienter, informer: I'organisation des services aux publiques dans les bibliothèques. Paris: Éditions du Cercle de la Librairie, 1996.

CAMPELLO, B. O movimento da competência informacional: uma perspectiva para o letramento informacional. Ciência da Informação, Brasília, v. 32, n. 3, p. 28-37, set./dez., 2003. Disponível em: 〈http://www.scielo.br/pdf/ci/v32n3/19021.pdf >. Acesso em: 03 out. 2016.

CORDÓN GARCÍA, J. A. Servicios de información y referencia. In: ORERA ORERA, L. (dir.). Manual de Biblioteconomía. Madrid: Síntesis, 1996. p. 265-288. Disponível em: <http://gredos.usal.es/jspui/bitstream/10366/83142/1/DBD_CordonGarcia_Serviciodeinforma cion.pdf>. Acesso em: 19 nov. 2016.

DASGUPTA, A. More than just a "reference librarian". The reference librarian, v. 54, p. 78-80, 2013. Disponível em: <http://www.tandfonline.com/doi/abs/10.1080/02763877.2013.738131?journalCode=wref2 > Acesso em: 16 out. 2016.

FIGUEIREDO, N. M. Técnicas e métodos para a avaliação de serviços de referênciainformação. Estudos Avançados em Biblioteconomia e Ciência da Informação, Brasília, v. 4, jan./dez., 1986. Disponível em:

<http://www.brapci.ufpr.br/index.php?dd60=1\&dd61=servi\%E7os\%20de\%20refer\%EAncia 


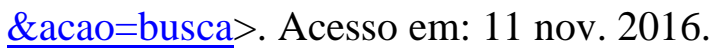

GROGAN, D. J. A prática do serviço de referência. Brasília: Briquet de Lemos, 1995.

LE BOTERF, G. Desenvolvendo a competência dos profissionais. 3. ed. rev. ampl. Porto Alegre: Artmed, 2003.

LEME, R. Aplicação prática da gestão de pessoas. Rio de Janeiro: Qualitymark, 2008.

MANGAS, S. F. A. Como planificar e gerir um serviço de referência. Biblios, ano 8, n. 2, abr./jun. 2007. Disponível em:

$<$ http://sisbib.unmsm.edu.pe/bibvirtualdata/publicaciones/biblios/n28/a02n28.pdf $>$. Acesso em: 16 nov. 2016.

MÁRDERO ARELlanO, M. Á. Serviço de referência virtual. Ciência da Informação, Brasília, v. 30, n. 2, p. 7-15, maio/ago. 2001. Disponível em:

<http://www.scielo.br/pdf/ci/v30n2/6206 $>$. Acesso em: 16 nov. 2016.

NAKANO, N.; JORENTE, M. J. V. Serviço de referência virtual: implantação do serviço de chat. Informação \& Informação, Londrina, v. 19, n. 1, p. 164-184, jan./abr. 2014.

Disponível em:

<http://www.uel.br/revistas/uel/index.php/informacao/article/view/15227/14212 >. Acesso em: 16 nov. 2016.

NUNES, T. As diferenças entre aulas expositivas e aulas dialogadas. 2012. Disponível em: <goo.gl/1Zj3Ww>. Acesso em: 15 mar. 2017.

TALAVERA IBARRA, A. M. El bibliotecólogo electrónico: consideraciones en torno al servicio de referencia en la era digital. Biblios, Lima, n. 3, 2000. Disponível em:

<http://www.redalyc.org/articulo.oa?id=16100301>. Acesso em: 08 nov. 2016.

TIMBÓ, N. V. O controle emocional do bibliotecário facilitando o processo de comunicação na entrevista de referência. Revista de Educação do Cogeime, São Paulo, n. 21, p. 83-89, dez. 2002. Disponível em: 〈http://www.cogeime.org.br/revista/cap0721.pdf〉. Acesso em: 18 jan. 2017.

WALLIS, J. Cyberspace information literacy and the information society. Library Review, [s.l.], v. 54, n. 4, p. 218-22, 2005. Disponível em:

<www.emeraldinsight.com/doi/pdf/10.1108/00242530510593407>. Acesso em: 04 out. 2016. 